Western University

Scholarship@Western

Department of Economics Research Reports

Economics Working Papers Archive

1977

Sterilization and the Monetary Approach to Balance of Payments Analysis

Russell S. Boyer

Follow this and additional works at: https://ir.lib.uwo.ca/economicsresrpt

Part of the Economics Commons

Citation of this paper:

Boyer, Russell S.. "Sterilization and the Monetary Approach to Balance of Payments Analysis." Department of Economics Research Reports, 7701. London, ON: Department of Economics, University of Western Ontario (1977). 


\section{Research Report 7701 \\ STERILIZATION AND THE MONETARY APPROACH \\ TO BALANCE OF PAYMENTS ANALYSIS}

Russell S. Boyer 


\title{
Sterilization and the Monetary Approach \\ to Balance of Payments Analysis
}

\author{
Russe11 S. Boyer \\ Department of Economics \\ University of Western Ontario
}

January 1977

The author would like to thank Peter Howitt, Clark Leith, and especially David Laidler and Michael Parkin for their extensive comments on an earlier draft of this paper. The financial assistance of Canada Council in supporting this research is gratefully acknowledged. 
Boyer, R. S.--Sterilization and the Monetary Approach to Balance of Payments Analys is

\begin{abstract}
An economy whose capital markets are not fully integrated with those of the rest of the world has the option of using changes in its interest rate so as to affect domestic money-holding. In this way the authorities can sterilize the balance of payments in both the short and long run. The degree of sterilization is an important determinant of the economy's equilibrium position. However, heavy sterilization causes the economy to be unstable.
\end{abstract}




\section{Sterilization and the Monetary Approach}

to Balance of Payments Analys is

\section{Introduction}

This paper analyzes, within a portfolio balance framework, the policy of sterilizing the money supply from the effects of a Balance of Payments surplus or deficit. All the results on sterilization (Munde11 (1968), Cooper (1969), Roper (1971), and Swoboda (1974)) have been derived within an outdated (and now widely recognized as inappropriate) specification of the capital account. 1

Earlier analyses of the balance of payments within a portfolio balance framework have been inapplicable to the sterilization issue in that they have assumed perfect capital mobility (Johnson (1972), and Frenkel and Rodriguez (1975)). Even extensions of that research to the case where there exists a nontraded or domestic bond (Boyer (1975), Dornbusch (1975), and Branson (1974)) are inappropriate as they stand for they treat the stock of that bond held by the private sector and the central bank as an exogenous variable. Within this framework and with these assumptions it has been impossible to analyze the process of sterilization. ${ }^{2}$

Sterilization appears to have been a widespread practise during the post-war decades. The most convincing scientific evidence reaching this conclusion is to be found in Kouri and Porter (1974) and Argy and Kouri (1974). There is also an enormous amount of casual empirical evidence from earlier periods, including the Gold-Standard period (Nurske (1944), Bloomfield (1959), Triffin (1969), and Yeager (1976)), which establishes that sterilization was used extensively. This evidence continues to be cited to counter any mechanical application of the Hume-price-specie-flow mechanism or the modern 
monetary approach to the balance of payments. ${ }^{3}$ As a result it is necessary to understand this process in order to be able to explain more fully the financial policies which have been prevalent in open economies.

Section II presents a simple model of a sma11, open economy that generates its own bond which is an imperfect substitute for internationally traded bonds. Section III models the authorities engaging in sterilization and shows how this affects the short-run behavior of the economy. Section IV introduces a saving function and investigates the model's longrun comparative static properties. Attention is called to the dangers of continued heavy. sterilization in Section $V$ where it is shown that the higher the degree of sterilization the slower the speed of adjustment until eventually the system becomes unstable. Conclusions are drawn in Section VI.

\section{The Mode1}

Consider a sma11, open economy, maintaining fixed exchange rates, which freely trades all its commodities with the rest of the world. ${ }^{4}$ The financial assets for the economy are domestic money, domestic bonds, 5 and international bonds. Denoting the individual's holdings of these assets by $M, B_{d}$ and $B_{t}$, respectively, his wealth is equal to the sum:

$$
W=M+B_{d}+B_{t}
$$

This equation, which describes every individual, holds also for the economy as a whole.

Individuals can trade these assets freely with each other and so can reach their optimal portfolio compositions The equations which characterize the optimal portfolio of the individual and therefore of the economy in aggregate are of the form: 


$$
\begin{aligned}
M= & l\left(r_{d}, r_{f}, W\right) \\
& b_{1}, b_{2}<0<b_{3} \\
B_{d}= & b\left(r_{d}, r_{f}, W\right) \\
& b_{1}, b_{3}>0>b_{2} \\
B_{t}= & b_{t}\left(r_{d}, r_{f}, W\right) 6 \\
& b_{t_{2}}, b_{t_{3}}>0>b_{t_{1}},
\end{aligned}
$$

where $r_{d}$ and $r_{f}$ are the rates of return on the domestic and traded bonds, respectively. The signs of the partial derivatives are dictated by the assumptions of wealth normality and gross substitutability. 7

The wealth constraint on the asset demand functions makes one of them redundant. Full information about the behavior of asset markets, in terms of rates of returns and supplies of assets held, can be obtained from any pair of equations in (2). Thus the following discussion can be conducted in terms of the money and domestic bond market equations.

The economy is assumed to be small in the commodities markets, so that their prices are given on the domestic market. A judicious choice of units permits the price of every commodity and the price index to be set equal to one. In addition, the economy takes the rate of return on the internationally-traded asset as exogenous since it is small in this market as we11. However, the rate of return on the domestic bond is endogenous to the sma11 economy.

In the short run the quantity of wealth can be taken as given. Each individual operates within his wealth constraint trading with others in order to obtain his optimal portfolio with the rates of return on all assets being exogenous. However, for the private sector as a whole the situation is quite different. The central bank controls the aggregate quantity of 
each asset available to be held. Open market operations are used to alter these supplies, but such operations leave the private sector's wealth unchanged.

The authorities cannot keep these asset supplies exogenous and maintain a fixed exchange rate, for then there would not be any mechanism to clear al1 the markets. Instead they must use transactions in at least two of these markets in order to peg the exchange rate. ${ }^{8}$ Their transactions are described by a reaction function $G\left(M_{,} B_{d}\right)$ which supplements the asset demand equations above (2). The system of equations then becomes:

$$
\begin{aligned}
M & =l\left(r_{d}, r_{f}, W\right) \\
B_{d} & =b\left(r_{d}, r_{f}, W\right) \\
G\left(M, B_{d}\right) & =0
\end{aligned}
$$

These equations can be understood most easily when put in a linearized form by differentiating:

$$
\begin{aligned}
d M & =l_{1} \cdot d r_{d}+l_{2} \cdot d r_{f}+b_{3} \cdot d W \\
d B_{d} & =b_{1} \cdot d r_{d}+b_{2} \cdot d r_{f}+b_{3} \cdot d W \\
\gamma \cdot d M & +(1-\gamma) \cdot d B_{d}=0
\end{aligned}
$$

where

$$
\gamma=\frac{G_{1}}{G_{1}+G_{2}} .
$$

That is, $\gamma$ is related to the ratio of the partial derivatives of the reaction function with respect to the money and domestic bond supplies. ${ }^{9}$ With such a framework a regime of sterilization of any degree can be modelled. When $\gamma=0$ the authorities use changes in the money supply to peg the exchange rate. The money supply is then completely free to vary so that there is no sterilization. An alternative way of characterizing this system is that 
authorities do not attach great importance to the supply of money (at least not so great as that which they attach to the exchange rate) and therefore it is an endogenous variable. In contrast, when the supply of domestic bonds is used to peg the exchange rate, $\gamma=1$. This is a regime of full sterilization in that now the supply of nontraded bonds is endogenous so as to keep both the exchange rate and the supply of money constant.

A regime of partial sterilization is one for which $0<\gamma<1$. In this case both assets' supplies are adjusted in the same direction so that either moves less than it would if it were the "pegging" variable under a pure sterilization regime. Sterilization in which the stocks of assets move in opposite direction are of two sorts: $\gamma<0$, called reverse sterilization; and $\gamma>1$, called super-sterilization. In reverse sterilization the money supply adjusts by so much that the supply of domestic bonds moves in the opposite direction from that which it would have followed under one hundred percent sterilization. In super-sterilization the domestic bond supply adjusts so strongly that the supply of money moves in the opposite direction from that without sterilization.

III. The Effects of Sterilization in the Short Run

The sterilization policy influences the effects which any exogenous change has upon the economy. The reason is that the sterilization regime shows the portfolio reallocation which the authorities permit, and this, in turn, effects the change in domestic rates of interest which are necessary to re-establish equilibrium.

Consider the short-run consequences of a rise in foreign rates of interest. During that time period wealth is constant but domestic rates of 
interest and holdings of assets are endogenous. Solving equation system (3) with the assumption that $d r_{f}$ is exogenous yields:

$$
\begin{aligned}
& \frac{\mathrm{dr}_{\mathrm{d}}}{\mathrm{dr}_{\mathrm{f}}}=-\frac{\mathrm{l}_{2} \circ \gamma-\mathrm{b}_{2}(1-\gamma)}{\Delta_{1}} \\
& \frac{\mathrm{dM}}{\mathrm{dr}_{f}}=\frac{\left(\mathrm{b}_{2} l_{1}-\mathrm{b}_{1} b_{2}\right)}{\Delta_{1}}(1-\gamma) \\
& \frac{\mathrm{dB}_{\mathrm{d}}}{\mathrm{dr}_{f}}=\frac{\left(\mathrm{b}_{2} l_{1}-\mathrm{b}_{1} l_{2}\right)}{\Delta_{1}} \gamma,
\end{aligned}
$$

where $\Delta_{1}=-b_{1}+\gamma\left(l_{1}+b_{1}\right)$ which is negative for values of $\gamma$ less than $\frac{b_{1}}{b_{1}+b_{1}}$ which is greater than one.

Under a regime of no sterilization $(\gamma=0)$ interest rates in the sma11 economy move in step with foreign rates. With this regime the supply of domestic bonds is exogenous so that the domestic rate of interest is set to counter the effects of foreign rates on the demand for these bonds. The foreign rate movement creates an excess supply of these assets. Therefore the domestic rate of interest must rise to offset this effect.

In contrast under a regime of complete sterilization $(\gamma=1)$ interest rates in the small economy move in the opposite direction from those in the rest of world. This regime holds the supply of money exogenous, so domestic rates must be adjusted to offset the influence of foreign rates on money demand. There is initially an excess supply of money. Individuals are willing to hold this excess so long as domestic rates are reduced, thus lowering the opportunity cost of holding money.

The authorities may wish to insulate domestic interest rates from the movements of foreign rates. The degree of sterilization which accomplishes this is: 


$$
\gamma=\frac{b_{2}}{l_{2}+b_{2}}
$$

This shows that the proportion in which the supplies of money and domestic bonds should be adjusted is just equal to the ratio of the excess supplies created in these markets on impact. This formula also demonstrates that the policy in general is one of partial sterilization, and this is consistent with the fact that the domestic rate of interest moves in opposite directions under the two polar sterilization regimes. Furthermore, this formula indicates that when money demand is unresponsive to foreign rates of interest $\left(\ell_{2}=0\right)$, the policy is one of complete sterilization. 10

The apparent similarity of the derivatives for the changes in the supplies of money and bonds with respect to foreign interest rates (equations (5) and (6)), hides the fact that they differ crucially in the way in which the degree of capital mobility influences their values.

The change in the domestic money supply, given by equation (5) above, simplifies to

$$
\frac{\mathrm{dM}}{\mathrm{dr}}=-\frac{\mathrm{b}_{2}}{\mathrm{~b}_{1}} \ell_{1}+\mathrm{l}_{2},
$$

as capital mobility increases so that $b_{1}$ and $b_{2}$ get indefinitely large。 However, these parameters enter the derivative as a ratio whose value is not importantly influenced by the size of either parameter independently. This demonstrates that the change in the supply of money with a change in foreign rates is not influenced crucially by the degree of capital mobility. In contrast, the change in the supply of domestic bonds, given by equation (6) above, simplifies to

$$
\frac{d B_{d}}{d r_{f}}=b_{2}-\frac{l_{2}}{l_{1}} b_{1}
$$


for the complete sterilization case. As capital mobility increases, the size of open market operations in domestic bonds necessary to sustain a complete sterilization equilibrium becomes indefinitely large. Because the domestic bond market is not so large as this, sterilization is not viable in the face of high capital mobility. This shows that sterilization may be unsustainable for an economy which permits its residents complete access to world capital markets. 11

IV. Sterilization in the Long Run

Sterilization can be pursued in the long run, as the process of asset accumulation occurs. In order to characterize the long-run equilibrium it is necessary to introduce the saving function which shows how holdings of financial assets adjust over time. For simplicity this function is taken to be a proportional one of the form:

$$
S=h \cdot\left(W *\left(r_{d}, r_{f}\right)-W\right),{ }^{12}
$$

showing that the rate of accumulation of financial assets is proportional to the difference between target holdings of nominal assets, $W^{*}$, and actual nominal wealth, where $h$ is the constant of proportionality.

In the long run holdings of nominal wealth are not changing because saving equals zero. Thus a further relation needs to be added to equations (3) above in order to show the endogeneity of wealth:

$$
W=W^{*}\left(r_{d}, r_{f}\right)
$$

or in differentiated form:

$$
d W=w_{1}^{*} \cdot d r_{d}+w_{2}^{*} \cdot d r_{f}
$$

The long-run consequences of a rise in foreign interest rates can now be investigated. The changes in the endogenous variables are: 


$$
\begin{aligned}
& \frac{d W}{d r_{f}}=\frac{-\left(w_{2}^{*} b_{1}-b_{2} W_{1}^{*}\right)+\gamma\left(\left(b_{1}+b_{1}\right) w_{2}^{*}-\left(l_{2}+b_{2}\right) W_{1}^{*}\right)}{\Delta_{2}} \\
& \frac{d r_{d}}{d r_{f}}=\frac{\left(b_{2}+b_{3} W_{2}^{*}\right)+\gamma\left(l_{2}+b_{2}\right)+\left(l_{3}+b_{3}\right) w_{2}^{*}}{\Delta_{2}} \\
& \frac{d M}{d r_{f}}=\frac{-(1-\gamma)\left(l_{2} b_{1}-b_{1} b_{2}+w_{1}^{*}\left(l_{2} b_{3}-b_{2} b_{3}\right)+w_{2}^{*}\left(l_{3} b_{1}-b_{3} b_{1}\right)\right)}{\Delta_{2}} \\
& \frac{d B_{d}}{d r_{f}}=\frac{-\gamma\left(l_{2} b_{1}-b_{1} b_{2}+w_{1}^{*}\left(l_{2} b_{3}-b_{2} b_{3}\right)+w_{2}^{*}\left(l_{3} b_{1}-b_{3} b_{1}\right)\right)}{\Delta_{2}}
\end{aligned}
$$

where $\Delta_{2}=-\left(b_{1}+b_{3} w_{1}^{*}\right)+\gamma\left(b_{1}+b_{1}+\left(b_{3}+b_{3}\right) w_{1}^{*}\right)$

which is negative so long as $\gamma$ is not large positively.

A11 these derivatives are of ambiguous sign in general. However, if money demand is more responsive to domestic than foreign rates (so that $\left.\ell_{1} W_{2}^{*}<\ell_{2} W_{1}^{*}\right)$, then wealth rises in the long run for partial- and reversesterilization regimes.

The important point that needs to be reiterated here is that sterilization is just as viable a policy in the long run as it is in the short run, Earlier conclusions to the contrary (Mundell (1968) and Swoboda (1974)) are the result of a misspecification of the capital account.

\section{The Process of Adjustment}

One of the drawbacks to having a sterilization regime is that the adjustment to a new steady-state equilibrium is slow. While this may not be a deficiency if, for some reason, fast adjustment is not desired, we find here that above a certain level the degree of sterilization causes the economy to become unstable. This is clearly an undesirable property of a policy regime. ${ }^{13}$ The speed of adjustment for a model of accumulation is quite gener- . ally equal to: 


$$
s=-\frac{d \frac{d W}{d t}}{d W}
$$

for this shows the rate at which any'increase in nominal wealth is lost to the rest of the world. In the case of an economy which is on fixed exchange rates and has perfect goods mobility, this speed is equal to

$$
s=-h \cdot\left(w_{1}^{*} \cdot \frac{d r_{d}}{d w}-1\right)
$$

showing that the reason that this speed is not equal simply to $h$ is that a change in wealth affects the donestic rate of interest. The effect of wealth on the interest rate can be ascertained from the equation system above (3). This yields:

$$
\frac{d r_{d}}{d W}=\frac{b_{3}-\gamma\left(b_{3}+b_{3}\right)}{-b_{1}+\gamma\left(b_{1}+b_{1}\right)}
$$

Therefore the speed of adjustment is equal to:

$$
s=-h\left[\frac{b_{1}+w_{1}^{*} \cdot b_{3}-\gamma\left(l_{1}+b_{1}+w_{1}^{*}\left(l_{3}+b_{3}\right)\right)}{-b_{1}+\gamma\left(b_{1}+b_{1}\right)}\right.
$$

The condition ror stability is $s>0$ which can be phrased as:

$$
w_{1}^{*}<\frac{-b_{1}+\gamma\left(b_{1}+b_{1}\right)}{b_{3}-\gamma\left(b_{3}+l_{3}\right)}
$$

This condition states that the model is stable so long as a rise in the domestic interest rate creates a smaller rise in (desired) wealth than that necessary to clear the asset markets. This assures that starting in long-run equilibrium a rise in wealth causes actual wealth to be above target wealth. This is the case because even though the increase in wealth may cause interest rates to rise in the short run (in the process of attaining portfolio balance) they do not rise by enough to make target wealth increase by even more. 
In the case of no sterilization the stability condition is clearly satisfied: a rise in domestic rates of interest creates an excess demand for domestic bonds such that wealth must be reduced to keep portfolios balanced with an unchanged supply of these assets. In the case of full sterilization the stability condition is:

$$
\mathrm{w}_{1}^{*}<-\frac{\ell_{1}}{\ell_{3}}
$$

and is not clearly satisfied. The reason is now a rise in interest rates creates an excess demand for money which can be eliminated by raising wealth; but the necessary $r$ ise in wealth may be greater than the increase in desired wealth.

Figure I shows the speed of adjustment as a function of the degree of sterilization. That functional relationship can be characterized as follows. For low and negative values of the sterilization coefficient the speed of adjustment is positive indicating that a conservative monetary stance is always stable. In particular, with no sterilization the speed of adjustment is greater than $h$ because a rise in wealth lowers rates of interest which accelerates the adjustment process to a higher speed than it would have if the excess wealth were permitted to drain off at unchanged rates. As the degree of sterilization is increased, the speed of adjustment is reduced. For a sterilization coefficient near one the model becomes unstable, in that the speed of adjustment becomes negative. The graph has a vertical symptote at $\gamma=\frac{b_{1}}{l_{1}+b_{1}}$ (which is greater than one). For higher values of the coefficient the speed again becomes positive, indicating stability, but now the short-run comparative statics are unintuitive and misleading. Thus, the general lesson to be drawn from this diagram is that conservative sterilization policies are more conducive to normal short-run behavior and to long-run stability. 14 


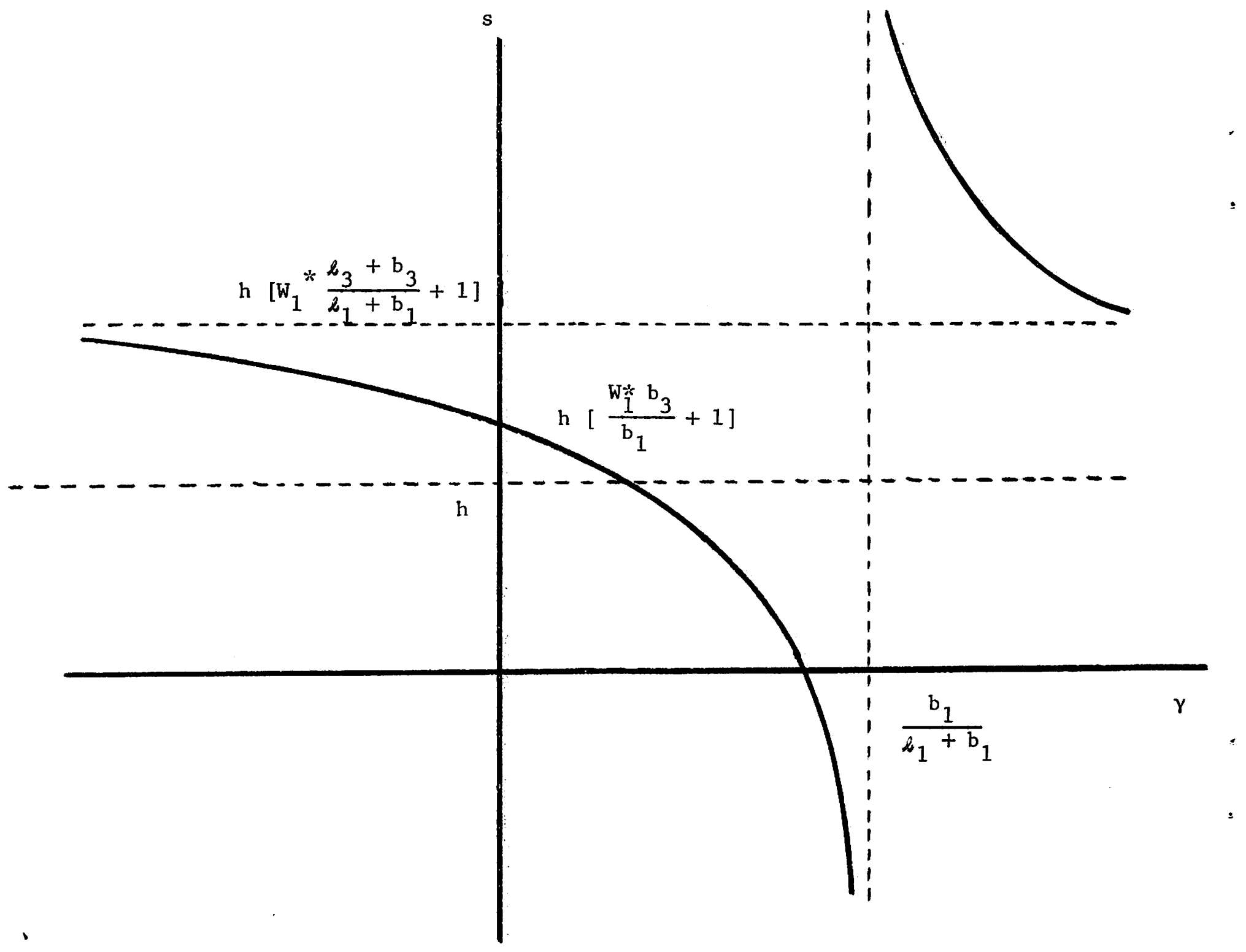

Figure I . 
VI. Conclusion

A small, fixed-exchange-rate economy, whose capital markets are not completely integrated with those of the rest of the world, has the option of using its rate of interest to influence the quantity of money held domestically. Such a policy of sterilization of the supply of money from the state of the balance of payments is viable so long as a portfolio balance view of the asset markets is justified. However, this policy is more difficult to conduct the closer the substitutability between domestic and foreign bonds, since the size of open market operations varies directly with this substitutability.

The short-run equilibrium of the economy depends upon the degree of sterilization and therefore an optimal degree can be found dependent upon the objective function and the exogenous shocks to which the economy is subjected. Similarly in the long run the degree of sterilization determines the nature of the equilibrium but now the response of the system to an exogenous shock, especially in the case of substantial sterilization, is ambiguous. Furthermore heavy sterilization can cause the economy to be unstable, moving it away from rather than towards this long-run equilibrium. Both these conclusions support the recommendation that sterilization be used sparingly as a short-run policy in the face of reversible shocks. 


\section{Footnotes}

$1_{\text {The traditional analysis of sterilization is done within the flow }}$ specification of the capital account. The conclusions derived from this model are that sterilization is possible in the short run (so long as capital is not perfectly mobile) but not in the long run. De Grauwe (1975) employs a partial adjustment model without rates of return. The present model assumes that portfolios are always in equilibrium.

${ }^{2}$ Sterilization of the balance of payments requires that the interest rate in the domestic economy be endogenous and alterable by the central Bank's transactions in assets other than money. In this way the quantity of money willingly held in the economy is set exogenously. For an alternative definition of sterilization, in which fiscal policy is employed, see McKinnon and Oates (1966).

$3_{\text {Many intermediate textbooks on international finance point out that }}$ the relationship between reserve and money supply changes was not very close, even during the period of the Gold Standard. See Whitman (1975) for a thoughtful discussion and summary of this evidence.

${ }^{4}$ This assumption is made merely for convenience, and in no way determines the conclusions which are derived.

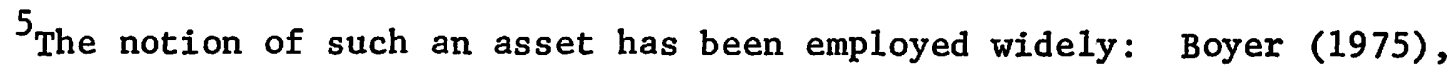
Branson (1974), Brunner and Meltzer (1976), Dornbusch (1975), and Girton and Henders on (1976).

${ }^{6}$ The wealth argument used in these demand functions is the time limit from the left of that variable. This assures that individuals do not demand indefinitely large quantities of assets, immediately adding them to their wealth so that the wealth constraint is always satisfied. 
${ }^{7}$ One result which follows directly from these assumptions is:

$$
-x_{1}<b_{1}
$$

This inequality is important in determining the sign of the system determinant below.

${ }^{8}$ It is well-known that if the supplies of assets are kept exogenous by the Central Bank, the economy is on flexible exchange rates. The open market operations which are employed by the authorities keep the value of domestic wealth constant by reducing the supply of one asset by the same amount that the supply of another is increased. In most cases internationallytraded bonds are the other side of the open market operation. As we show here whether the money market or the domestic bond market is the other half of the intervention scheme is of great importance. A further disaggregation of internationally-traded assets into bonds and reserves is not carried out here.

${ }^{9}$ Although this equation is identified as a reaction function, it serves merely to represent mathematically the alternative methods open to the authorities to peg the exchange rate. There is no optimization involved in its formulation. A more general function, including the domestic rate of interest as an argument, can be reduced to that given here.

10 Munde11 (1968, p. 225) argues that this is the likely case and shows diagrammatically that a policy of sterilization keeps nominal income constant in the face of the foreign interest rate change.

11 Mundell (1968, p. 261) is careful to note that sterilization is not viable only if capital is perfectly mobile. Swoboda (1974) is not so conscientious on this point.

12 The conditions on the utility function necessary to yield a saving function similar to this one are given in Dornbusch and Mussa (1975). 
13 This conclusion is operationally equivalent to previous results about sterilization: the economy may never reach long-run equilibrium under such a regime.

${ }^{14}$ For points to the right of the vertical asymptote the system determinant is of positive sign, whereas to the left of that line it is of negative sign. 
REFERENCES

Argy, V., and P. Kouri (1974), "Sterilization policies and the volatility of international reserves," in R. Z. Aliber (ed.), National and International Monetary Policies (Chicago).

Bloomfield, A. I. (1959), Monetary Policy Under the International Gold Standard: 1880-1914, Federal Reserve Bank of New York.

Boyer, R. S. (1975), "Commodity markets and bond markets in a small, fixedexchange-rate economy," Canadian Journal of Economics, 8, 1-23.

Branson, W. H. (1974), "Stocks and flows in international monetary analysis," in A. Ando, R. Herring, and R. Marston (eds.), International Aspects of Stabilization Policies, Federal Reserve Bank of Boston, 12, 27-50.

Brunner, K. and A. Meltzer (1976), "Monetary and fiscal policy in open, interdependent economies with fixed exchange rates," in E. M. Claassen and P. Salin (eds.), Recent Issues in Internationa1 Monetary Economics, North-Holland (Amsterdam).

Cooper, R. N. (1969), "Macroeconomic policy adjustment in interdependent economies," Quarterly Journal of Economics, 83, 1-22.

De Grauwe, P. (1975), "The interaction of monetary policies in a group of European countries," Journal of International Economics, 5, 207-228. Dornbusch, R. (1975), "A portfolio balance model of the open economy," Journal of Monetary Economics, 1, 3-20.

Dornbusch, R. and M. Mussa (1975), "Consumption, real balances, and the hoarding function," International_Economic Review, 16, 415-421.

Frenke1, J. and C. Rodriguez (1975), "Portfolio equilibrium and the balance of payments: a monetary approach," American Economic Review, 65, 647-688.

Girton, L. and D. W. Henderson (1976), "Financial capital movements and central bank behavior in a two-country, short-run portfolio balance mode1," Journal of Monetary Economics, 2, 33-61. 
Johnson, H. G。 (1972), "The monetary approach to the balance of payments," in H. G. Johnson, Further Essays in Monetary Economics, London: A1len and Unwin.

Kouri, P. J. K. and M. G. Porter (1974), "International capital flows and portfolio equilibrium," Journal of Political Economy, 82, 443-467. McKinnon, R. and W. E. Oates (1966), "The implications of international economic integration for monetary, fiscal, and exchange-rate policy," Studies in International Finance (International Finance Section, Princeton, N.J.), 16.

Munde11, R. A. (1968), International Economics, Macmillan (New York). Nurkse, R. (1944), International Currency Experience, League of Nations. Roper, E. D。 (1971), "Macroeconomic policies and the distribution of the world money supply," Quarterly Journal of Economics, 85, 119-146.

Swoboda, A. K. (1974), "Monetary policy under fixed exchange rates: effectiveness, : the speed of adjustment, and proper use," in H. G. Johnson and A. R。 Nobay (eds.), Issues in Monetary Economics, Oxford University Press, 52-74. Triffin, R. (1969), "The myth and realities of the so-called gold standard," in R. No Cooper (ed.), International Finance: Selected Readings, Penguin Modern Economics (Harmondsworth, England), 38-61.

Whitman, M。 N. (1975), "Global monetarism and the monetary approach to the balance of payments," Brookings Papers on Economic Activity, 3, 491-555. Yeager, L。 B. (1976), International Monetary Relations: Theory, History and Policy, Harper and Row (Evanston), second edition. 